\title{
Ankara koşullarında aspire uygulanan farklı azotlu gübre dozlarının verim ve verim öğelerine etkileri
}

\section{The Effects of Different Nitrogen Fertilizer Doses on the Yield and Yield Parameters of Safflower in Ankara Conditions}

\author{
Mehtap GÜRSOY $^{1^{*} \text { iD }}$, Dilek BAŞALMA ${ }^{2}$ iD , Farzad NOFOUZI ${ }^{3}$ iD \\ ${ }^{1}$ Aksaray Üniversitesi, Güzelyurt Meslek Yüksekokulu, Güzelyurt/AKSARAY \\ ${ }^{2}$ Ankara Üniversitesi, Ziraat Fakültesi, Tarla Bitkileri Bölümü, Dışkapı/ANKARA \\ ${ }^{3}$ Ondokuz Mayıs Üniversitesi, Zootekni Bölümü, Kurupelit/SAMSUN
}

To cite this article:

Gürsoy, M., Başalma, D. \& Nofouzi, F. (2019). Ankara koşullarında aspire uygulanan farklı azotlu gübre dozlarının verim ve verim öğelerine etkileri. Harran Tarım ve Gıda Bilimleri Dergisi, 23(2):167177.

DOI:

10.29050/harranziraat.4041 94

Address for Correspondence: Mehtap GÜRSOY

e-mail:

mehtapgrsoy@gmail.com

Received Date:

11.03.2018

Accepted Date:

25.04.2019

(C) Copyright 2018 by Harran University Faculty of Agriculture. Available on-line at www.dergipark.gov.tr/harranziraat
Öz

Aspir, iklim ve toprak istekleri diğer yağ bitkilerine göre daha az olan, kurağa dayanıklı bir bitkidir. Bu çalışma, aspir genotiplerine uygulanan farklı azot dozlarının verim ve verim öğeleri üzerine etkilerinin belirlenmesi amacıyla,2015 ve 2016 yıllarında, Ankara koşullarında, yürütülmüştür. Materyal olarak, Dinçer, Linas aspir çeşitleri ile Bahri Dağdaş Uluslararası Tarımsal Araştırma Enstitüsü tarafından geliştirilen 1 hat (BDUTAE Hattı) ve amonyum sülfat gübresinin farklı dozları $\left(0,5\right.$ ve $\left.15 \mathrm{~kg} \mathrm{da}^{-1}\right)$ kullanılmıştır. Araştırma Tesadüf Bloklarında Faktöriyel Deneme Desenine göre, üç tekerrürlü olarak kurulmuştur. Çalışma sonuçlarına göre; tohum verimi bakımından birinci yılda, en yüksek değer $160.3 \mathrm{~kg} \mathrm{da}^{-1}$ olarak BDUTAE Hattı ve 5 $\mathrm{kg} \mathrm{da}^{-1}$ azot dozunda elde edilirken ikinci yılda ise, $175.0 \mathrm{~kg} \mathrm{da}{ }^{-1}$ olarak Dinçer çeşidinde ve $5 \mathrm{~kg}$ $\mathrm{da}^{-1}$ azot uygulamasından, elde edilmiştir. Yağ oranı incelendiğinde ise, birinci yılda, Dinçer çeşidinde $5 \mathrm{~kg} \mathrm{da}^{-1}$ azot dozunda en yüksek \%39.94 olan değer ikinci yılda, \% 40.77 olarak Linas çeşidinde ve kontrol uygulamasında saptanmıştır. Yağ verimi ise birinci yılda, $56.67 \mathrm{~kg} \mathrm{da}^{-1}$ olarak $5 \mathrm{~kg} \mathrm{da}^{-1}$ azot dozunda, Dinçer çeşidinde, çalışmanın ikinci yılında ise, $56.63 \mathrm{~kg} \mathrm{da}{ }^{-1}$ olarak Linas çeşidinden, kontrol uygulamasında elde edilmiştir. Sonuç olarak, uygulanan azot dozları arasında, verim ve verim öğeleri bakımından çok önemli farklılıklar belirlenmediğinden, dekara $5 \mathrm{~kg}$ azot ve aspir çeşitlerinden ise, Linas önerilebilir.

Anahtar Kelimeler: Carthamus tinctorius L., Azot dozu, Genotip, Tohum verimi, Yağ oranı

\section{ABSTRACT}

Safflower is a drought tolerant crop plant with less environmental and soil requirements compared to other oilseed plants. This study was carried out in Ankara to determine the effects of different nitrogen doses on the yield and yield components applied to safflower genotypes in 2015 and 2016.Different doses (0,5 and $15 \mathrm{~kg} \mathrm{da}^{-1}$ ) of ammonium sulphate were applied to safflower cv. Dinçer, Linas and a safflower line developed by Bahri Dağdaş International Agricultural Research Institute (BDUTAE Line)were used as material. The research was set up according to Factorial Random Blocks design with three replications. The highest yield of $160.3 \mathrm{~kg} \mathrm{da}^{-1}$ and $175.0 \mathrm{~kg} \mathrm{da}^{-1}$ was obtained from the first and second year using cV. BDUTAE Line and cv. Dinçer after application of $5 \mathrm{~kg} \mathrm{da}^{-1}$ nitrogen each in the same order. The highest oil content of $39.94 \%$ (cv. Dinçer and at the dose of $5 \mathrm{~kg} \mathrm{da}^{-1}$ nitrogen doses during first year) and $40.77 \%$ (control- during second year) was noted from cv. Linas. Oil yield $\left(56.67 \mathrm{~kg} \mathrm{da}^{-1}\right.$ ) was obtained from the Dinçer variety at the dose of $5 \mathrm{~kg}$ $\mathrm{da}^{-1}$ nitrogen in the first year. The second year of the study the highest oil yield was obtained $56.63 \mathrm{~kg} \mathrm{da}^{-1}$ from the control and cv. Linas. As there are no significant differences between the applied nitrogen doses in terms of yield and yield parameters, the $\mathrm{cv}$. Linas of safflower can be best suggested for cultivation using $5 \mathrm{~kg} \mathrm{da}^{-1}$ nitrogen dose.

Key Words: Carthamus tinctorius L.,Nitrogen dose, Genotype, Seed yield, Oil content 


\section{Giriş}

Aspir, yalancı safran, Amerikan safranı veya boyacı safranı gibi isimlerle de bilinen, tek yıllık, sarı, kırmızı, turuncu, renklerde çiçekleri olan, dikenli ve dikensiz, kurağa dayanıklı, ortalama yağ oranı \%30-50 arasında değişebilen bir yağ bitkisidir (Gürsoy ve ark., 2015). Yazlık ve kışlık olarak yetiştirilebilen aspir bitkisi, yarı kurak bölgelerde, toprak derinliği ve verimliliği az olan yerlerde birim alan verimi yüksek olan bir bitkidir (Koç ve ark., 2009). Tohumundan elde edilen yağın yemeklik kalitesinin yüksek olmasının yanı sıra, yarı kuruyan özellikte olması sebebiyle de boya sanayinde de oldukça önemlidir (Yıldırım ve ark., 2005). Günümüzde sınırlı alanlarda ekilmesi ve üretiminin az olmasına rağmen (Akbulut, 2019) diğer yağ bitkilerine nazaran kurak bölgelere adaptasyon yeteneğinin daha yüksek oluşu, bu bitkinin yakın bir gelecekte öneminin daha da artacağı umudunu vermektedir (Baydar ve Gökmen, 2003). Ayrıca, aspir tohumlarında bulunan yağın yaklaşık \%90'ı doymamış yağ asitlerinden olan linoleik(Omega-6) ve oleik (Omega-9) asitten oluşmaktadır (Johnson et al., 1999).

Aspir bitkisinde azotlu gübreleme ile ilgili çalışmalar yapılmış olup; Yıldırım ve ark., (2005) yaptıkları çalışmada aspir bitkisine farklı azot ve fosfor dozları uygulamışlar ve çalışma sonucunda azot dozlarının bitki boyu, bitki başına tabla sayısı, tohum verimi ve ham yağ verimi üzerine olumlu etki yaptığını bildirmişlerdir. Soleymani ve Shahrajabian(2011), aspir bitkisinde farklı azot dozları uygulayarak yaptıkları çalışmada uygulanan azotun bitki boyu, ilk dal yüksekliği, ikincil dal sayısı, tabla sayısı, tablada tohum sayısı, 1000 tohum ağırlı̆ı ve tohum verimi özelliklerinde olumlu etkiye sahip olduğunu bildirmişlerdir. Bu çalışmanın amacı ise, Ankara koşullarında bazı aspir çeşit ve hattına uygulanan azotlu gübre dozlarının verim ve verim öğelerine etkilerinin belirlenmesidir.

\section{Materyal ve Yöntem}

Bu araştırma, 2015 ve 2016 yıllarında Ankara Üniversitesi Ziraat Fakültesi deneme arazisinde yürütülmüştür. Deneme alanı engebesiz olup, deniz seviyesinden yüksekliği 860 m'dir. Materyal olarak Dinçer ve Linas aspir çeşitleri ile Bahri Dağdaş Uluslararası Tarımsal Araştırma Enstitüsü tarafından geliştirilen 1 hat(BDUTAE Hattı) kullanılmıştır. Azotlu gübre olarak ise, kontrol (0), 5 ve $15 \mathrm{~kg} \mathrm{da}^{-1}$ saf azot olacak şekilde amonyum sülfat gübresi kullanılmıştır. Aspir bitkisinin vejetasyon dönemine ait uzun yıllar, 2015 ve 2016 yıllarına ait meteorolojik veriler Çizelge 1 'de ve deneme yıllarında yapılan toprak analizi sonuçları ise Çizelge 2'de verilmiştir.

Çizelge 1.Deneme yerinin ortalama uzun yıllar, 2015 ve 2016 yıllarına ait meteorolojik verileri*

Table 1. The meteorologica Idata of the experiment location for long term and the years of 2015 and 2016

\begin{tabular}{|c|c|c|c|c|c|c|c|c|c|}
\hline & \multicolumn{3}{|c|}{$\begin{array}{l}\text { Yağış Toplamı }(\mathrm{mm}) \\
\text { Total Rainfall }(\mathrm{mm})\end{array}$} & \multicolumn{3}{|c|}{$\begin{array}{c}\text { Ortalama Sicaklık ( C) } \\
\text { Average temperature (C) }\end{array}$} & \multicolumn{3}{|c|}{$\begin{array}{c}\text { Nispi Nem (\%) } \\
\text { Relative Humidity(\%) }\end{array}$} \\
\hline & 2015 & 2016 & $\begin{array}{c}\text { Uzun } \\
\text { Yıllar } \\
\text { Long Years }\end{array}$ & 2015 & 2016 & $\begin{array}{c}\text { Uzun } \\
\text { Yıllar } \\
\text { Long Years }\end{array}$ & 2015 & 2016 & $\begin{array}{c}\text { Uzun } \\
\text { Yillar } \\
\text { Long Years }\end{array}$ \\
\hline $\begin{array}{l}\text { Mart } \\
\text { March }\end{array}$ & 87.4 & 78.5 & 41.3 & 7.1 & 8,0 & 6.1 & 66.3 & 63.0 & 64.2 \\
\hline $\begin{array}{l}\text { Nisan } \\
\text { April }\end{array}$ & 23.3 & 17.2 & 47.5 & 9.1 & 14.3 & 11.2 & 55.9 & 49.7 & 59.5 \\
\hline $\begin{array}{l}\text { Mayıs } \\
\text { May }\end{array}$ & 53.1 & 46.6 & 51.7 & 16.9 & 15.1 & 15.8 & 54.9 & 62.1 & 57.4 \\
\hline $\begin{array}{l}\text { Haziran } \\
\text { June }\end{array}$ & 110.8 & 18.8 & 37.5 & 18.3 & 22.0 & 19.8 & 68.4 & 48.9 & 52.7 \\
\hline $\begin{array}{l}\text { Temmuz } \\
\text { July }\end{array}$ & 2.7 & 0.0 & 14.2 & 24.2 & 25.0 & 23.3 & 43.2 & 39.2 & 45.4 \\
\hline $\begin{array}{l}\text { Ağustos } \\
\text { August }\end{array}$ & 24.0 & 60.6 & 13.4 & 24.6 & 25.3 & 23.2 & 46.8 & 46.2 & 45.1 \\
\hline $\begin{array}{l}\text { Toplam } \\
\text { Total }\end{array}$ & 448.2 & 441.0 & 412.5 & & & & & & \\
\hline
\end{tabular}


Meteorolojik veriler incelendiğinde, 2015 ve 2016 yıllarında alınan yıllık toplam yağış, uzun yıllar ortalamasından biraz yüksek olarak gerçekleşmiştir. Özellikle 2015 yılı Haziran ayında, çok ekstrem bir (110.8 mm) yağış kaydedilmiştir. Aylık ortalama sıcaklık ve aylık ortalama nispi nem bakımından, deneme yıllarında, bitkinin vejetasyon dönemi boyunca, uzun yıllar ortalamasına yakın değerler kaydedilmiştir (Çizelge 1).

Çizelge 2. Deneme yerinin 2015 ve 2016 yıllarına ait toprak analizi sonuçları

Table 2. Analysis results of soil samples taken from the experiment locatio, on 2015 and 2016 years

\begin{tabular}{cccccccccc}
\hline Yıllar & $\begin{array}{c}\mathrm{N} \\
(\%)\end{array}$ & $\begin{array}{c}\mathrm{P} \\
(\mathrm{ppm})\end{array}$ & $\mathrm{K}(\mathrm{ppm})$ & $\mathrm{pH}$ & $\begin{array}{c}\text { Organik } \\
\text { madde(\%) } \\
\text { Organic Material }\end{array}$ & $\begin{array}{c}\text { Kireç }(\%) \\
\text { Lime }\end{array}$ & $\begin{array}{c}\mathrm{EC}(\mathrm{dS} / \mathrm{m}) \\
\text { Electrical } \\
\text { Conductivity }\end{array}$ & $\begin{array}{c}\text { Tekstür } \\
\text { Texture }\end{array}$ \\
\hline 2015 & 0.03 & 10.34 & 598 & 7.88 & 1.18 & 5.97 & 0.19 & $\mathrm{Kil}$ \\
2016 & 0.07 & 13.28 & 582 & 8.02 & 1.48 & 5.39 & 3.04 & $\mathrm{Kil}$ \\
\hline
\end{tabular}

Kaynak: Ankara Üniversitesi Ziraat Fakültesi Bitki Besleme Anabilim Dalı Laboratuvarı

Reference: Ankara University Agriculture Faculty Plant Nutrition Department Laboratory

Deneme yerinden alınan toprak örneklerinde yapılan analiz sonuçlarını gösteren Çizelge 2 incelendiğinde; deneme toprağının hafif alkali reaksiyonda ve killi tekstüre sahip olduğu görülmektedir. Fosfor içeriği yeterli düzeyde olup, organik madde yetersiz ve potasyum fazla miktardadır. Araştırma Tesadüf bloklarında faktöriyel deneme desenine göre üç tekerrürlü olarak kurulmuştur. Parsellerden her biri $5 \mathrm{~m}$ uzunluğunda ve 4 sıradan oluşmuştur. Sıra araları $35 \mathrm{~cm}$ 'dir. Tüm deneme alanına her iki yılda da, eşit olarak $8 \mathrm{~kg} \mathrm{da}{ }^{-1} \mathrm{P}_{2} \mathrm{O}_{5}$ hesabıyla triple süper fosfat gübresi ekimden önce uygulanmıştır. Araştırmanın birinci yılında 16 Mart 2015 tarihinde, ikinci yılında ise 17 Mart 2016 tarihinde ekim yapılmıştır. Ekimle beraber azotlu gübre uygulamalarının yarısı saf azot olacak şekilde, diğer yarısı ise çiçeklenme başlamadan bitkiler tam olgunluk boyuna ulaşmadan önce uygulanmıştır. Denemelerin yürütüldüğü yıllarda Mayıs ayının ilk haftası ve son haftasında çapalama ve seyreltme yapılmıştır. Denemede iki defa sulama yapılmıştır. İlk sulama, ekimden hemen sonra çıkışı garantilemek amacıyla, ikinci sulama da, Nisan ayının son haftasında, bitkilerde su ihtiyacının görülmesi nedeni ile yapılmıştır. Meteorolojik verilerin incelenmesinden de görülebileceği gibi; her iki yılda da, Nisan ayı yağışları uzun yıllar ortalamasından oldukça düşüktür. Denemede yapılan gözlemler sonucunda bitkilerin hasat olgunluğuna geldiği dönemlerde, yani 1. Yılında, 30 Temmuz 2015, 2. yılında ise 29 Temmuz 2016 tarihinde, hasat yapılmıştır. Her iki yılda da, bütün parsellerden tesadüfi seçilen 10 bitkide, bitki boyu, yan dal sayısı, bitki başına tabla sayısı, tabladaki tohum sayısı, bin tohum ağırlığı, tohum verimi, yağ oranı ve yağ verimi incelenmiştir. Harman sonrası, her bir uygulamaya ait öğütülmüş aspir tohumu kullanılarak, ham yağ (\%) analizleri, Ankara Üniversitesi Ziraat Fakültesi Tarla Bitkileri Bölümü Laboratuvarı'nda Gerhardt marka, soxhlet cihazında yapılmıştır(Anonim, 2018). Elde edilen veriler Tesadüf Bloklarında Faktöriyel Deneme Desenine göre Mstat-C istatistiki analiz yöntemine tabi tutularak varyans analizleri yapılmıştır. Uygulamalar arasındaki farklılıkların önem düzeyleri ise, Duncan testi ile belirlenmiştir (Düzgüneş ve ark., 1987).

\section{Bulgular ve Tartışma}

\section{Bitki boyu}

Aspir genotiplerine uygulanan farklı azot dozlarının bitki boyuna ilişkin varyans analiz sonuçları incelendiğinde, yıllar arasında, istatistiki bakımdan önemli fark görülmüştür. Denemenin 1. yılında (2015), genotipler arasında $p<0.05$, dozlar arasında ise $p<0.01$ düzeyinde önemli fark saptanmıştır. Denemenin 2. Yılında (2016) ise, genotipler ve dozlar arasında $p<0.01$, genotipler $x$ dozlar interaksiyonunda ise $p<0.05$ düzeyinde önemli fark bulunmuştur. Aspir genotiplerine uygulanan farklı azot dozlarının, bitki boyuna etkisine ilişkin ortalama değerler Çizelge 3'te verilmiştir. 
Çizelge 3. Farklı azot dozlarının aspir genotiplerinin bitki boyuna etkisine ilişkin ortalama değerler

Table 3. Effect of the different nitrogen doses of safflower genotypes on the average values of the plant height

\begin{tabular}{|c|c|c|c|c|c|c|c|c|}
\hline \multirow[b]{3}{*}{$\begin{array}{l}\text { Genotip } \\
\text { Genotypes }\end{array}$} & \multicolumn{8}{|c|}{$\begin{array}{c}\text { Bitki Boyu }(\mathrm{cm}) \\
\text { Plant Height }(\mathrm{cm})\end{array}$} \\
\hline & \multicolumn{4}{|c|}{2015} & \multicolumn{4}{|c|}{2016} \\
\hline & $\begin{array}{c}0 \\
\mathrm{~kg} \mathrm{da}^{-1}\end{array}$ & $\begin{array}{c}5 \\
\mathrm{~kg} \mathrm{da}^{-1}\end{array}$ & $\begin{array}{c}15 \\
\mathrm{~kg} \mathrm{da}^{-1}\end{array}$ & $\begin{array}{l}\text { Ortalama } \\
\text { Average }\end{array}$ & $\begin{array}{c}0 \\
\mathrm{~kg} \mathrm{da} a^{-1}\end{array}$ & $\begin{array}{c}5 \\
\mathrm{~kg} \mathrm{da}\end{array}$ & $\begin{array}{c}15 \\
\mathrm{~kg} \mathrm{da}^{-1}\end{array}$ & $\begin{array}{l}\text { Ortalama } \\
\text { Average }\end{array}$ \\
\hline Dinçer & 72.66 & 86.81 & 82.64 & $80.71 b$ & $78.45 \mathrm{CD}$ & $86.65 \mathrm{~B}$ & $88.43 \mathrm{~B}$ & $84.51 b$ \\
\hline BDUTAE & 79.96 & 89.76 & 81.87 & $83.87 \mathrm{a}$ & $82.88 \mathrm{BC}$ & $97.88 \mathrm{~A}$ & 86.87 B & $89.21 \mathrm{a}$ \\
\hline Linas & 79.33 & 88.65 & 85.52 & $84.50 \mathrm{a}$ & $75.92 \mathrm{D}$ & $87.89 \mathrm{~B}$ & 86.37 B & $83.39 \mathrm{~b}$ \\
\hline \multicolumn{9}{|l|}{ Ortalama } \\
\hline Average & $77.32 c^{*}$ & $88.41 \mathrm{a}$ & $83.35 \mathrm{~b}$ & & 79.08 b & $90.81 \mathrm{a}$ & $87.23 \mathrm{a}$ & \\
\hline
\end{tabular}

Çizelge 3 incelendiğinde; 2015 yılına ait bitki boyu ortalama değerlerinde en kısa bitki boyu $77.32 \mathrm{~cm}$ olarak kontrol uygulamasından, en uzun bitki boyu da $88.41 \mathrm{~cm}$ ile $5 \mathrm{~kg} \mathrm{da}^{-1}$ azot uygulamasından elde edilmiştir. Genotipler arasında en kısa bitki boyu $80.71 \mathrm{~cm}$ ile Dinçer çeşidinden elde edilmiş olup, en uzun bitki boyu $84.50 \mathrm{~cm}$ ile Linas çeşidinde saptanmıştır. Denemenin 2. yılında (2016) ise, en kısa bitki boyu $75.92 \mathrm{~cm}$ ile Linas çeşidinin kontrol uygulamasından elde edilirken, en uzun bitki boyu $97.88 \mathrm{~cm}$ ile BDUTAE Hattına uygulanan $5 \mathrm{~kg} \mathrm{da}^{-1}$ azot dozunda saptanmıştır. Bitki boyu bakımından görülen bu farklılıkların yıllar arasındaki iklim farkından kaynaklandığı düşünülmektedir. Çeşitlerin genetik yapılarının farklı olması ve çevre koşullarının da etkisi ile uygulamaların etkilerinin farklı olabileceği araştırıcılar tarafından ifade edilmektedir (Öztürk ve ark., 2009). Yıldırım ve ark., (2005) aspir çeşitlerine farklı azot ve fosfor dozları uyguladıkları çalışmada, azot ve fosfor dozları arasındaki interaksiyonun önemli olduğunu ve aspirde en uzun bitki boyunu 68.93 $\mathrm{cm}$ olarak saptadıklarını bildirmişlerdir. Arslan ve Bayraktar (2015) aspir bitkisine uygulanan farklı azot ve fosfor dozlarının etkilerini belirlemek amacıyla yaptıkları çalışmada; en kısa bitki boyunu kontrol uygulamasından, en uzun bitki boyunu $(93.0 \mathrm{~cm})$ ise, $9 \mathrm{~kg} \mathrm{da}^{-1}$ fosfor ve $20 \mathrm{~kg} \mathrm{da}^{-1}$ azot uygulamasından elde ettiklerini bildirmişlerdir. Katar ve ark., (2015) bölünerek uygulanan azotlu gübre dozlarının aspir çeşidine etkilerini inceledikleri çalışmada; yıllar ve uygulamalar arasında önemli düzeyde farklılıklar saptadıklarını bildirmişlerdir. Bununla beraber, ortalama bitki boyunu $75.74 \mathrm{~cm}$ olarak bulduklarını ifade etmişlerdir. Bu çalışmada bitki boyu özellikle $5 \mathrm{~kg}$ $\mathrm{da}^{-1}$ azot dozunda daha fazla artış göstermiştir.

\section{Yan dal sayısı}

Yan dal sayılarına ilişkin varyans analizi sonucunda; denemenin 1. Yllında, dozlar arasında $p<0.01,2$. yılında ise, $p<0.05$ düzeyinde önemli fark bulunmuştur. Aspir genotiplerine uygulanan farklı azot dozlarının an dal sayısına ilişkin ortalama değerler çizelge 4'teverilmiştir.

Çizelge 4. Farklı azot dozlarının aspir genotiplerinin yan dal sayısına etkisine ilişkin ortalama değerler

Table 4. Effect of average values of the number of lateral branches of safflower genotypes of different nitrogen doses

\begin{tabular}{|c|c|c|c|c|c|c|c|c|}
\hline \multirow[b]{3}{*}{$\begin{array}{l}\text { Genotip } \\
\text { Genotypes }\end{array}$} & \multicolumn{8}{|c|}{$\begin{array}{c}\text { Yan Dal Sayısı (adetbitki }{ }^{-1} \text { ) } \\
\text { Number of lateral branch (numberplant }{ }^{-1} \text { ) }\end{array}$} \\
\hline & \multicolumn{4}{|c|}{2015} & \multicolumn{4}{|c|}{2016} \\
\hline & $\begin{array}{c}0 \\
\mathrm{~kg} \mathrm{da}^{-1}\end{array}$ & $\begin{array}{c}5 \\
k g ~ d a\end{array}$ & $\begin{array}{c}15 \\
\mathrm{~kg} \mathrm{da}^{-1}\end{array}$ & $\begin{array}{l}\text { Ortalama } \\
\text { Average }\end{array}$ & $\begin{array}{c}0 \\
\mathrm{~kg} \mathrm{da}^{-1}\end{array}$ & $\begin{array}{c}5 \\
k g ~ d a-1\end{array}$ & $\begin{array}{c}15 \\
\mathrm{~kg} \mathrm{da}^{-1}\end{array}$ & $\begin{array}{l}\text { Ortalama } \\
\text { Average }\end{array}$ \\
\hline Dinçer & 13.06 & 15.66 & 13.50 & 14.07 & 13.66 & 14.80 & 12.66 & 13.71 \\
\hline BDUTAE & 11.70 & 14.56 & 13.83 & 13.36 & 15.13 & 16.40 & 13.76 & 15.10 \\
\hline Linas & 11.63 & 14.65 & 13.46 & 13.25 & 13.40 & 14.10 & 13.96 & 13.82 \\
\hline \multicolumn{9}{|l|}{ Ortalama } \\
\hline Average & $12.13 b^{*}$ & $14.96 \mathrm{a}$ & $13.60 \mathrm{a}$ & & $14.07 \mathrm{ab}$ & $15.10 \mathrm{a}$ & $13.47 b$ & \\
\hline
\end{tabular}

*Harfler dozlara ait farklı grupları göstermektedir

*The letters show different groups of doses 
Azot dozları arasında 1. yılda en fazla yan dal sayısı 14.96 adet bitki ${ }^{-1}$ ile $5 \mathrm{~kg} \mathrm{da}^{-1}$ azot uygulamasında, en az 12.13 adet bitki ${ }^{-1}$ ile kontrol uygulamasından elde edilmiştir. Denemenin 2. yılında ise, en az yan dal sayısı $15 \mathrm{~kg} \mathrm{da}^{-1}$ uygulamasında, en fazla yan dal sayısı (15.10 adet bitki $\left.^{-1}\right) 5 \mathrm{~kg} \mathrm{da}^{-1}$ uygulamasından elde edilmiştir (Çizelge 4). Bitkilerde dallanmanın çeşit özelliği olmasına karşın yapılan uygulamalar ve ekolojik faktörlerden etkilendiği araştırıcılar tarafından bildirilmektedir (Gencer ve ark., 1987). Öztürk ve ark., (2009) sulu ve kuru koşullarda denemeye aldıkları aspir çeşitlerinin yan dal sayısını sulu koşullarda daha fazla saptadıklarını bildirmişlerdir. Arslan ve Bayraktar (2015) farklı azot ve fosfor seviyelerinin kuru şartlarda yetiştirilen aspir bitkisinin bazı verim özelliklerine etkisini incelemek amacıyla yaptıkları çalışmada denemenin özellikle 1. yılında en yüksek yan dal sayısını 6.3 adet bitki ${ }^{-1}$ olarak en fazla azotlu gübre uygulamasından $(20 \mathrm{~kg} / \mathrm{da})$ elde ettiklerini bildirmişlerdir. Kaya ve ark., (2015) aspir hat ve çeşitleri ile Eskişehir koşullarında yaptıkları çalışmada, en fazla yan dal sayısını 43/11 aspir hattında $\quad 4.60 \quad$ adet olarak bildirmişlerdir.Çalışmada elde ettiğimiz sonuçlar, önceki çalışmalara göre yüksek olup, bunun nedeninin yetiştirme tekniği özellikle ekim sıklığı vb. farklılıklardan veya iklim ve toprak koşullarından kaynaklandığı düşünülmektedir.

\section{Bitkide tabla sayısı}

Bitkide tabla sayısı bakımından; denemenin 1. yılında genotipler arasında $p<0.01$, dozlar arasında ise $p<0.05,2$. yılında ise dozlar arasında $p<0.01$ düzeyinde önemli farklılıklar belirlenmiştir. Azot dozlarının incelenen aspir genotiplerinin bitkide tabla sayısına ilişkin ortalama değerleri Çizelge 5'te verilmiştir.

Çizelge 5. Farklı azot dozlarının aspir genotiplerinin bitki başına tabla sayısına etkisine ilişkin ortalama değerler Table 5. Effect of average values of the number of tray the safflower genotypes of different nitrogen doses

\begin{tabular}{|c|c|c|c|c|c|c|c|c|}
\hline \multirow[b]{3}{*}{$\begin{array}{l}\text { Genotip } \\
\text { Genotypes }\end{array}$} & \multicolumn{8}{|c|}{$\begin{array}{l}\text { Bitki Başına Tabla Sayısı (adet) } \\
\text { Tray number per plant (number) }\end{array}$} \\
\hline & \multicolumn{4}{|c|}{2015} & \multicolumn{4}{|c|}{2016} \\
\hline & $\begin{array}{c}0 \\
k g ~ d a-1\end{array}$ & $\mathrm{~kg} \mathrm{da}^{-1}$ & $\begin{array}{c}15 \\
\mathrm{~kg} \mathrm{da}^{-1}\end{array}$ & $\begin{array}{l}\text { Ortalama } \\
\text { Average }\end{array}$ & $\begin{array}{c}0 \\
\mathrm{~kg} \mathrm{da}^{-1}\end{array}$ & $\mathrm{~kg} \mathrm{da}^{-1}$ & $\begin{array}{c}15 \\
\mathrm{~kg} \mathrm{da}^{-1}\end{array}$ & $\begin{array}{l}\text { Ortalama } \\
\text { Average }\end{array}$ \\
\hline Dinçer & 12.03 & 12.80 & 11.30 & $12.04 \mathrm{~b}$ & 12.83 & 15.26 & 15.10 & 14.40 \\
\hline BDUTAE & 12.33 & 14.26 & 13.23 & $13.28 \mathrm{a}$ & 13.53 & 16.23 & 14.63 & 14.80 \\
\hline Linas & 14.06 & 14.93 & 14.07 & $14.36 \mathrm{a}$ & 14.26 & 15.56 & 14.23 & 14.68 \\
\hline \multicolumn{9}{|l|}{ Ortalama } \\
\hline Average & $12.81 b^{*}$ & $14.00 \mathrm{a}$ & $12.87 b$ & & $13.54 \mathrm{~b}$ & $15.69 \mathrm{a}$ & $14.66 \mathrm{ab}$ & \\
\hline
\end{tabular}

*Küçük harfler genotip ve dozlara ait farklı grupları göstermektedir

*Small letters show different groups of genotypes and doses

Bitki başına tabla sayısı bakımından çizelge 5 incelendiğinde, 1. deneme yılında, dozlar bakımından en az bitki başına tabla sayısı kontrol uygulamasında 12.81 adet, en fazla tabla sayısı ise, 14.00 adet olarak $5 \mathrm{~kg} \mathrm{da}{ }^{-1}$ dozunda saptanmıştır. Genotipler bakımından ise, en az tabla sayısı Dinçer çeşidinde (12.04 adet), en fazla tabla sayısı ise 14.36 adet olarak Linas çeşidinde belirlenmiştir. Denemenin 2. yılında ise, dozlar bakımından en az tabla sayısı 13.54 adet olarak kontrol uygulamasında, en fazla tabla sayısı ise, 15.69 adet ile $5 \mathrm{~kg} \mathrm{da}^{-1}$ gübre uygulamasında elde edilmiştir. Özel ve ark., (2004) Şanlıurfa koşullarında farklı ekim zamanı ve mesafeleri kullanarak yaptıkları çalışmada aspir çeşidinde en yüksek tabla sayısını 9.90 adet bitki ${ }^{-1}$ olarak saptadıklarını bildirmişlerdir. Zareie et al., (2011) azot ve demir gübrelemesinin aspir bitkisinde tohum verimi ve verim öğelerine etkilerini inceledikleri çalışmada en fazla bitki başına tabla sayısını azotlu gübre olarak $100 \mathrm{~kg} \mathrm{ha}^{-1}$ azot uygulaması yapılan parsellerden elde ettiklerini bildirmişlerdir. Katar ve ark., (2012) Ankara koşullarında farklı azot dozları uyguladıkları aspir çeşidinde tabla sayısını $20 \mathrm{~kg} \mathrm{da}^{-1}$ azot dozunda en fazla 19.53 adet olarak saptadıklarını bildirmişlerdir. Köse ve Bilir (2017) aspirde farklı 
sıra arası ve ekim normu uygulamalarının etkilerini araştırdıkları çalışmada denemenin 1. yılında 10.8 adet bitki ${ }^{-1}, 2$. yılında ise 17.8 adet bitki $^{-1}$ tabla sayısı değerleri elde ettiklerini bildirmişlerdir. Aspirde tohum verimini belirleyen seleksiyon kriterlerinden en önemlisinin bitki başına tabla sayısı olduğu araştırıcılar tarafından ifade edilmektedir (Uysal ve ark., 2006). Bu çalışmada da en yüksek tabla sayısı her iki yılda $\mathrm{da}, 5 \mathrm{~kg} \mathrm{da}^{-1}$ azot dozundan elde edilmiştir.

\section{Tablada tohum sayısı}

Aspirgenotiplerine uygulanan farklı azot dozlarının, tablada tohum sayısına ilişkin varyans analiz sonuçlarına göre; denemenin 1. Yılında, genotip ve genotipxdozlar interaksiyonu arasında $p<0.01$, 2. yılında ise, genotip $x$ dozlar interaksiyonu arasında $p<0.01$ düzeyinde önemli farklar saptanmıştır. Aspir genotiplerine uygulanan farklı azot dozlarının bitki başına tabla sayısına ilişkin ortalama değerler Çizelge $6^{\prime} \mathrm{da}$ verilmiştir.

Çizelge 6. Farklı azot dozlarının aspir genotiplerinin tablada tohum sayısına etkisine ilişkin ortalama değerler Table 6. Effect of average values for the number of seeds on the tray of safflower genotypes different nitrogen doses

\begin{tabular}{|c|c|c|c|c|c|c|c|c|}
\hline \multirow[b]{3}{*}{$\begin{array}{l}\text { Genotip } \\
\text { Genotypes }\end{array}$} & \multicolumn{8}{|c|}{$\begin{array}{c}\text { Tablada Tohum Sayısı (adet) } \\
\text { Seed number per tray (number) }\end{array}$} \\
\hline & \multicolumn{4}{|c|}{2015} & \multicolumn{4}{|c|}{2016} \\
\hline & $\begin{array}{c}0 \\
k g d a^{-1}\end{array}$ & $\begin{array}{c}5 \\
\mathrm{~kg} \mathrm{da}^{-1}\end{array}$ & $\begin{array}{c}15 \\
k g ~ d a^{-1}\end{array}$ & $\begin{array}{l}\text { Ortalama } \\
\text { Average }\end{array}$ & $\begin{array}{c}0 \\
\mathrm{~kg} \mathrm{da}^{-1}\end{array}$ & $\begin{array}{c}5 \\
k g d a^{-1}\end{array}$ & $\begin{array}{c}15 \\
\mathrm{~kg} \mathrm{da}^{-1}\end{array}$ & $\begin{array}{l}\text { Ortalama } \\
\text { Average }\end{array}$ \\
\hline Dinçer & $23.00 \mathrm{C}$ & $26.00 \mathrm{BC}$ & $26.33 \mathrm{BC}$ & $25.11 b$ & $28.67 \mathrm{BC}$ & $31.67 \mathrm{BC}$ & $31.00 \mathrm{BC}$ & 30.44 \\
\hline BDUTAE & $22.33 \mathrm{C}$ & $28.33 \mathrm{AB}$ & $27.33 \mathrm{ABC}$ & $26.00 \mathrm{ab}$ & $30.33 \mathrm{BC}$ & $33.67 \mathrm{AB}$ & $30.33 \mathrm{BC}$ & 31.44 \\
\hline Linas & $31.33 A^{*}$ & $25.00 \mathrm{BC}$ & $27.33 \mathrm{ABC}$ & 27.89 a & $37.67 \mathrm{~A}$ & $30.33 \mathrm{BC}$ & $27.33 \mathrm{C}$ & 31.77 \\
\hline $\begin{array}{l}\text { Ortalama } \\
\text { Average }\end{array}$ & 25.55 & 26.44 & 27.00 & & 32.22 & 31.88 & 29.55 & \\
\hline
\end{tabular}

*Küçük harfler genotiplere ait, büyük harfler interaksiyona ait farklı grupları göstermektedir

* Small letters show genotypes, capital letters show different groups of interaction

Çizelge 6.'da denemenin 1. Yılında, genotipxdozlar interaksiyonu bakımından, tablada tohum sayısına ait ortalama değerler incelendiğinde, en az değer BDUTAE Hattının kontrol uygulamasından 22.33 adet ve en fazla tablada tohum sayısı 31.33 adet olarak Linas çeşidinin kontrol uygulamasından elde edildiği görülmektedir. Çalışmanın 2. yılında ise, tabladaki tohum sayısı en düşük 27.33 adet olarak Linas çeşidinin $15 \mathrm{~kg} \mathrm{da}^{-1} \mathrm{~N}$ uygulamasından elde edilirken en fazla değer ise, Linas çeşidinde 37.67 adet olarak kontrol parselinde belirlenmiştir. Uysal ve ark.,(2006) Isparta koşullarında yaptıkları iki yıllık çalışmada, tablada tohum sayısını çeşitler ortalaması olarak 21.9 adet olarak saptadıklarını bildirmişlerdir. Arslan ve Bayraktar (2015) farklı azot ve fosfor seviyelerinin kuru şartlarda yetiştirilen aspir bitkisinde, tabladaki tohum sayısını ortalama 28.64 adet olarak saptadıklarını bildirmişlerdir. En fazla tabladaki tohum sayısını $15 \mathrm{~kg} \mathrm{da}^{-1} \mathrm{~N}$ dozunda belirlemişlerdir. $\mathrm{Bu}$ çalışmada gözlemlediğimiz tabladaki tohum sayıları da, araştırıcıların bulguları ile uyumludur. Aspir bitkisinde tablada tohum sayısının da önemli bir verim kriteri olarak kabul edildiği araştırıcılar tarafından bildirilmektedir (Uysal ve ark., 2006).

\section{Tohum verimi}

Aspir genotiplerine uygulanan farklı azot dozlarının tohum verimine ilişkin varyans analiz sonuçlarına göre, denemenin 1. Yılında, dozlar arasında $p<0.01$, genotipxdozlar interaksiyonu arasında ise $p<0.05$, çalışmanın 2. yılında da, dozlar arasında $p<0.05$ ve genotipxdozlar interaksiyonu arasında $p<0.01$ düzeyinde önemli fark bulunmuştur. Aspir genotiplerine uygulanan farklı azot dozlarının tohum verimine ilişkin ortalama değerler Çizelge 7'de verilmiştir. 
Çizelge 7. Farklı azot dozlarının aspir genotiplerinin tohum verimine etkisine ilişkin ortalama değerler Table 7. Effect of average values of seed yield of safflower genotypes different nitrogen doses

\begin{tabular}{|c|c|c|c|c|c|c|c|c|}
\hline \multirow[b]{3}{*}{$\begin{array}{l}\text { Genotip } \\
\text { Genotypes }\end{array}$} & \multicolumn{8}{|c|}{$\begin{array}{c}\text { Tohum Verimi }\left(\mathrm{kg} \mathrm{da}^{-1}\right) \\
\text { Seed Yield }\left(\mathrm{kg} \mathrm{da}^{-1}\right)\end{array}$} \\
\hline & \multicolumn{4}{|c|}{2015} & \multicolumn{4}{|c|}{2016} \\
\hline & $\begin{array}{c}0 \\
k g d a^{-1}\end{array}$ & $\begin{array}{c}5 \\
\mathrm{~kg} \mathrm{da}^{-1}\end{array}$ & $\begin{array}{c}15 \\
\mathrm{~kg} \mathrm{da}^{-1}\end{array}$ & $\begin{array}{l}\text { Ortalama } \\
\text { Average }\end{array}$ & $\begin{array}{c}0 \\
k g \mathrm{da}^{-1}\end{array}$ & $\begin{array}{c}5 \\
\mathrm{~kg} \mathrm{da}^{-1}\end{array}$ & $\begin{array}{c}15 \\
\mathrm{~kg} \mathrm{da}^{-1}\end{array}$ & $\begin{array}{c}\text { Ortalama } \\
\text { Average }\end{array}$ \\
\hline Dinçer & $140.1 \mathrm{D}$ & $147.0 \mathrm{CD}$ & $156.2 \mathrm{AB}$ & 147.73 & $140.6 \mathrm{C}$ & $175.0 \mathrm{~A}$ & $156.8 \mathrm{BC}$ & 157.45 \\
\hline BDUTAE & $144.8 \mathrm{CD}$ & $160.3 \mathrm{~A}$ & $150.0 \mathrm{BC}$ & 151.70 & $152.6 \mathrm{BC}$ & $153.0 \mathrm{BC}$ & $151.3 \mathrm{BC}$ & 152.29 \\
\hline Linas & $149.3 \mathrm{BC}^{*}$ & $158.0 \mathrm{AB}$ & $151.2 \mathrm{BC}$ & 152.84 & $161.4 \mathrm{AB}$ & $151.2 \mathrm{BC}$ & 147.4 BC & 153.33 \\
\hline Ortalama & & & & & & & & \\
\hline Average & $144.71 b$ & $155.11 \mathrm{a}$ & $152.45 \mathrm{ab}$ & & $151.5 \mathrm{~b}$ & $159.7 \mathrm{a}$ & $151.8 \mathrm{~b}$ & \\
\hline
\end{tabular}

Tohum verimi bakımından ortalama değerleri içeren Çizelge 7 incelendiğinde; 2015 yılında genotipxdozlar interaksiyonu bakımından en az tohum verimi (140.1 $\mathrm{kg} \mathrm{da}^{-1}$ ) kontrol dozunda ve Dinçer çeşidinde belirlenmiş olup, en yüksek tohum verimi ise $160.3 \mathrm{~kg} \mathrm{da}^{-1}$ ile BDUTAE Hattı ve $5 \mathrm{~kg} \mathrm{da}^{-1}$ azot uygulamasından elde edilmiştir. 2016 yılında ise, en az tohum verimi (140.6 kg da$\left.{ }^{1}\right)$ yine kontrol uygulamasında ve Dinçer çeşidinde saptanırken, en yüksek tohum verimi $175.0 \mathrm{~kg} \mathrm{da}$ 1 olarak $5 \mathrm{~kg} \mathrm{da}^{-1}$ azot dozunda ve Dinçer çeşidinde belirlenmiştir. Özel ve ark., (2002) Harran ovası koşullarında aspir çeşitlerinin verim ve bazı tane özelliklerini inceledikleri çalışmada en yüksek tohum verimini $111.7 \mathrm{~kg} \mathrm{da}{ }^{-1}$ olarak belirlediklerini bildirmişlerdir. Çamaş ve ark., (2007) Kuzey Türkiye şartlarında yetiştirdikleri aspir bitkisinin dekara tohum verimini en fazla Gümüşhacıköy lokasyonunda $248.2 \mathrm{~kg}$ olarak bildirmişlerdir. Koç ve ark., (2009) Konya şartlarında aspir ekim zamanını belirlemek amacıyla yaptıkları çalışmada 15 Şubat, 1 Mart, 15 Mart, 1 Nisan, 15 Nisan ve 1 Mayıs olmak üzere altı ekim zamanı ve Dinçer ve Remzibeyaspir çeşitleri kullanmışlardır. Çalışma sonucunda en yüksek tohum verimi 15 Şubat tarihindeki ekimlerden Remzibey çeşidinden ortalama 465.75 $\mathrm{kg} \mathrm{da}^{-1}$ alınırken; en düşük tohum verimini ise 1 Mayıs tarihinde yapılan ekimden Dinçer çeşidinden ortalama $52 \mathrm{~kg} \mathrm{da}{ }^{-1}$ olarak saptadıklarını bildirmişlerdir. Arslan ve Bayraktar (2015) farklı fosfor ve azot dozu uygulamalarının aspirde tohum verimini artırıcı önemli bir faktör olduğunu saptadıklarını bildirmişlerdir. Sampaio et al., (2016) tropikal koşullarda gübre uygulamalarının tohum ve yağ verimini iyileştirmesiyle ilgili yaptıkları çalışmada tohum verimini ortalama ilkbahar ve kış ekimlerinde sırasıyla 2068 ve $3820 \mathrm{~kg} \mathrm{ha}^{-1}$ olarak saptadıklarını bildirmişlerdir. Bu çalışmada da, en yüksek tohum verimi için optimum doz $5 \mathrm{~kg} \mathrm{da}{ }^{-1}$ olarak belirlenmiştir. Araştırmada elde edilen sonuçlar, diğer araştırıcılarınkinden düşük olup; bunun sebebinin genotiplerin farklı oluşu, iklim ve toprak koşulları olduğu düşünülmektedir.

\section{Bin tohum ağırlı̆̆ı}

Aspir genotiplerine uygulanan farklı azot dozlarının bin tohum ağırlığına ilişkin varyans analiz sonuçları incelendiğinde her iki yılda da genotipler arasındaki farklılık $p<0.05$ düzeyinde önemli bulunmuştur. Farklı azot dozlarının aspir genotiplerinin bin tohum ağırlığına etkisine ilişkin ortalama değerler çizelge $8^{\prime}$ de sunulmuştur. 
Çizelge 8.Farklı azot dozlarının aspir genotiplerinin bin tohum ağırlığına etkisine ilişkin ortalama değerler Table 8. Effect of average values of thousand seed weight of safflower genotypes different nitrogen doses

\begin{tabular}{|c|c|c|c|c|c|c|c|c|}
\hline \multirow[b]{3}{*}{$\begin{array}{l}\text { Genotip } \\
\text { Genotypes }\end{array}$} & \multicolumn{8}{|c|}{$\begin{array}{l}\text { Bin Tohum Ağırlığı (g) } \\
\text { Thousand seed weight (g) }\end{array}$} \\
\hline & \multicolumn{4}{|c|}{2015} & \multicolumn{4}{|c|}{2016} \\
\hline & $\begin{array}{c}0 \\
\mathrm{~kg} \mathrm{da}^{-1}\end{array}$ & $\begin{array}{c}5 \\
\mathrm{~kg} \mathrm{da}^{-1}\end{array}$ & $\begin{array}{c}15 \\
\mathrm{~kg} \mathrm{da}^{-1}\end{array}$ & $\begin{array}{l}\text { Ortalama } \\
\text { Average }\end{array}$ & $\begin{array}{c}0 \\
\mathrm{~kg} \mathrm{da}^{-1}\end{array}$ & $\begin{array}{c}5 \\
\mathrm{~kg} \mathrm{da}^{-1}\end{array}$ & $\begin{array}{c}15 \\
\mathrm{~kg} \mathrm{da}^{-1}\end{array}$ & $\begin{array}{l}\text { Ortalama } \\
\text { Average }\end{array}$ \\
\hline Dinçer & 33.23 & 33.93 & 34.10 & $33.76 c^{*}$ & 34.00 & 35.00 & 35.27 & 34.76 abc \\
\hline BDUTAE & 36.13 & 36.13 & 34.27 & $35.51 \mathrm{a}$ & 33.50 & 34.43 & 35.2 & 34.41 bc \\
\hline Linas & 33.97 & 33.70 & 35.77 & $34.71 \mathrm{ab}$ & 35.27 & 35.30 & 36.60 & 35.91 a \\
\hline Ortalama & & & & & & & & \\
\hline Average & 34.44 & 34.59 & 34.71 & & 34.48 & 34.88 & 35.72 & \\
\hline
\end{tabular}

*Küçük harfler genotiplere ait farklı grupları göstermektedir

*Small letters show different groups of genotypes

Bin tohum ağırlığı bakımından ortalama değerleri içeren Çizelge 8incelendiğinde; denemenin 1.yılında en düşük bin tohum ağırlığı $33.76 \mathrm{~g}$ ile Dinçer, en yüksek bin tohum ağırlığı ise $35.51 \mathrm{~g}$ olarak BDUTAE Hattında belirlenmiştir. Denemenin 2. yılında en az bin tohum ağırlığı $34.41 \mathrm{~g}$ BDUTAE Hattında, en fazla ise, $35.91 \mathrm{~g}$ Linas çeşidinde saptanmıştır. Öztürk ve ark., (2009) sulu ve kuru koşullarda yetiştirdikleri aspir çeşitlerinin bin tohum ağırlığı değerinin sulu koşullarda $40.5 \mathrm{~g}$, kuru koşullarda ise $37.3 \mathrm{~g}$ olarak belirlendiğini bildirmişlerdir. Adalı (2016) aspir bitkisinde yaptığı çalışmada bin tohum ağırlığı değerini $32.77-43.28 \mathrm{~g}$ arasında değiştiğini bildirmiştir. Katar ve ark.,(2015) bölünerek uygulanan azotlu gübre dozlarının aspir çeşidine etkilerini inceledikleri çalışmada ortalama bin tohum ağırlığını $46.1 \mathrm{~g}$ olarak saptadıklarını bildirmişlerdir. Yılmaz ve Güllüoğlu (1999) bin tohum ağırlığının verimi belirleyen faktörlerden biri olduğunu ve yüksek olmasının arzu edildiğini bildirmişlerdir. Bu çalışmada elde edilen bulgular araştırıcılarınki ile uyumludur.

\section{Yağ oranı}

Aspir genotiplerine uygulanan farklı azot dozlarının yağ oranına etkisine ilişkin varyans analiz sonuçları incelendiğinde her iki yılda da, genotipler arasında $p<0.01$ düzeyinde önemli farklılıklar belirlenmiştir. Yağ oranına ilişkin ortalama değerler çizelge 9'da verilmiştir.

Çizelge 9. Farklı azot dozlarının aspir genotiplerinin yağ oranına etkisine ilişkin ortalama değerler

Table 9. Effect of mean values of oil percentage of safflower genotypes different nitrogen doses

\begin{tabular}{|c|c|c|c|c|c|c|c|c|}
\hline \multirow[b]{3}{*}{$\begin{array}{l}\text { Genotip } \\
\text { Genotypes }\end{array}$} & \multicolumn{8}{|c|}{$\begin{array}{c}\text { Yağ Oranı (\%) } \\
\text { OilRatio (\%) }\end{array}$} \\
\hline & \multicolumn{4}{|c|}{2015} & \multicolumn{4}{|c|}{2016} \\
\hline & $\begin{array}{c}0 \\
k g d a^{-1}\end{array}$ & $\begin{array}{c}5 \\
k g d a^{-1}\end{array}$ & $\begin{array}{c}15 \\
\mathrm{~kg} \mathrm{da}^{-1}\end{array}$ & $\begin{array}{l}\text { Ortalama } \\
\text { Average }\end{array}$ & $\begin{array}{c}0 \\
\mathrm{~kg} \mathrm{da}^{-1}\end{array}$ & $\begin{array}{c}5 \\
k g d a^{-1}\end{array}$ & $\begin{array}{c}15 \\
\mathrm{~kg} \mathrm{da}^{-1}\end{array}$ & $\begin{array}{l}\text { Ortalama } \\
\text { Average }\end{array}$ \\
\hline Dinçer & 39.24 & 39.94 & 39.13 & 39.44a* & 35.67 & 36.08 & 38.21 & $36.65 \mathrm{~b}$ \\
\hline BDUTAE & 38.94 & 38.20 & 36.28 & $37.81 \mathrm{ab}$ & 39.01 & 38.89 & 38.21 & $38.71 \mathrm{a}$ \\
\hline Linas & 37.30 & 38.81 & 37.33 & $37.81 \mathrm{ab}$ & 40.77 & 37.83 & 39.07 & $39.22 \mathrm{a}$ \\
\hline Ortalama & & & & & & & & \\
\hline Average & 38.49 & 37.81 & 37.81 & & 38.48 & 37.60 & 38.50 & \\
\hline
\end{tabular}

*Küçük harfler genotiplere ait farklı grupları göstermektedir

* Small letters show different groups of genotypes

Çalışmanın 1. yılında en düşük yağ oranı \%37.81 olarak BDUTAE Hattı ve Linas çeşitlerinde, en yüksek \%39.44 olarak Dinçer çeşidinde belirlenmiştir. 2. yılda en düşük oran 36.65 ile Dinçer çeşidinde, en yüksek ise \%39.22 olarak
Linas çeşidinde belirlenmiştir (Çizelge 9). Uysal ve ark., (2006) iki yıllık yaptıkları çalışmada yağ oranını 1. yıl \%21.8-26.3 arasında, 2.yılda ise \%25.0-27.8 arasında belirlediklerini bildirmişlerdir. Özel ve ark., (2004) Şanlıurfa koşullarında aspir çeşidinde uygun ekim zamanı 
ve sıra üzeri aralığını belirlemek amacıyla yaptıkları çalışmada yağ oranını \% 35.48- 25.66 olarak saptadıklarını bildirmişlerdir. Katar ve ark., (2015) ortalama yağ oranı \%26.44 olarak belirlediklerini bildirmişlerdir. Kaya ve ark., (2015) bazı ileri kademe aspir hatlarının Eskişehir koşullarındaki performanslarını inceledikleri çalışmalarında, en fazla yağ oranını \% 36.6 olarak saptamışlardır. Arslan ve Bayraktar (2016) farklı azot ve fosfor seviyelerinin Ankara koşullarında, Dinçer aspir bitkisinin bazı özelliklerine etkisini inceledikleri çalışmada, yağ oranının araştırmanın birinci yılında \% 21.33-27.83, ikinci yılında ise \% 22.87-27.33 arasında değişiklik gösterdiğini bildirmişlerdir. Bazı araştırıcıların bulguları bu çalışmada elde edilen yağ oranı değerlerinden düşüktür. Ham yağ oranlarının yüksek oluşu nedeni; genotiplerin farklılığından, ekim sıklığı gibi yetiştirme tekniklerinden veya iklim ve toprak şartlarından kaynaklandığı düşünülmektedir.

\section{Yağ verimi}

Aspir genotiplerine uygulanan farklı azot dozlarının yağ verimine ilişkin varyans analiz sonuçları incelendiğinde her iki yılda da genotipler ile genotipxdozlar interaksiyonlarında $p<0.01$ düzeyinde önemli fark görülmektedir. Yağ verimine ilişkin ortalama değerler Çizelge 10 'da verilmiştir.

Çizelge 10.Farklı azot dozlarının aspir genotiplerinin yağ verimine etkisine ilişkin ortalama değerler

Table 10. Effect of mean values of oil yield of safflower genotypes different nitrogen doses

\begin{tabular}{|c|c|c|c|c|c|c|c|c|}
\hline \multirow[b]{3}{*}{$\begin{array}{r}\text { Genotip } \\
\text { Genotypes }\end{array}$} & \multicolumn{8}{|c|}{$\begin{array}{c}\text { Yağ Verimi }\left(\mathrm{kg} \mathrm{da}^{-1}\right) \\
\text { Oil Yield }\left(\mathrm{kg} \mathrm{da}^{-1}\right)\end{array}$} \\
\hline & \multicolumn{4}{|c|}{2015} & \multicolumn{4}{|c|}{2016} \\
\hline & $\begin{array}{r}0 \\
k g d a^{-1}\end{array}$ & $\mathrm{~kg} \mathrm{da}^{-1}$ & $\mathrm{~kg} \mathrm{da}^{-15}$ & $\begin{array}{l}\text { Ortalama } \\
\text { Average }\end{array}$ & $\mathrm{kg} \mathrm{da}^{0}$ & $\mathrm{~kg} \mathrm{da}^{5}$ & $\mathrm{~kg} \mathrm{da}^{15}$ & $\begin{array}{l}\text { Ortalama } \\
\text { Average }\end{array}$ \\
\hline Dinçer & $51.53 \mathrm{C}-\mathrm{F}$ & $56.67 \mathrm{~A}$ & $50.27 \mathrm{DEF}$ & $52.82 b^{*}$ & $48.43 \mathrm{~F}$ & $49.40 \mathrm{EF}$ & $49.33 \mathrm{EF}$ & $49.06 \mathrm{c}$ \\
\hline BDUTAE & $51.77 \mathrm{C}-\mathrm{F}$ & 50.00 DEF & $52.93 \mathrm{~A}-\mathrm{E}$ & 51.57 bc & $54.57 \mathrm{ABC}$ & $52.37 \mathrm{~B}-\mathrm{F}$ & 53.07 A-E & $53.33 \mathrm{ab}$ \\
\hline Linas & $48.43 \mathrm{~F}$ & $53.50 \mathrm{~A}-\mathrm{D}$ & $52.27 \mathrm{~B}-\mathrm{F}$ & 51.40 bc & $56.63 \mathrm{~A}$ & $55.93 \mathrm{AB}$ & $54.23 \mathrm{ABC}$ & $55.60 \mathrm{a}$ \\
\hline $\begin{array}{l}\text { Ortalama } \\
\text { Average }\end{array}$ & 50.58 & 53.39 & 51.82 & & 53.21 & 52.57 & 52.21 & \\
\hline
\end{tabular}

*Küçük harfler genotiplere ait, büyük harfler interaksiyona ait farklı grupları göstermektedir

* Small letters show genotypes, capital letters show different groups of interaction

Yağ verimi ait ortalama değerleri içeren çizelge 10incelendiğinde; çalışmanın 1. yılında en düşük yağ verimi $48.43 \mathrm{~kg} \mathrm{da}{ }^{-1}$ olarak kontrol uygulamasında ve Linas çeşidinde belirlenmiştir. En yüksek yağ verimi ise $56.67 \mathrm{~kg} \mathrm{da}^{-1}$ ile $5 \mathrm{~kg} \mathrm{da}^{-1}$ azot dozu uygulamasında ve Dinçer çeşidinde saptanmıştır. Çalışmanın 2. yılında ise, en düşük yağ verimi $48.43 \mathrm{~kg} \mathrm{da}{ }^{-1}$ olarak kontrol uygulamasında ve Dinçer çeşidinde belirlenirken, en yüksek yağ verimi $56.63 \mathrm{~kg} \mathrm{da}{ }^{-1}$ olarak kontrol parselinde Linas çeşidinde belirlenmiştir. Yıldırım ve ark., (2005) en yüksek ham yağ verimi ortalamasının $85.92 \mathrm{~kg} \mathrm{da} a^{-1}$ olarak elde edildiğini bildirmişlerdir. Öztürk ve ark., (2009) sulu ve kuru koşullarda yaptıkları çalışmada ham yağ verimini en yüksek $62.4 \mathrm{~kg} \mathrm{da}^{-1}$ ile sulu parsellerden, kuru parsellerde ise bu değerin \% 57.7'lik bir azalışla $26.4 \mathrm{~kg} \mathrm{da}^{-1}$ a gerilediğini belirlemişlerdir. Aydın (2012) Karadeniz bölgesi koşullarında yaptığı çalışmada ham yağ verimi 14.67-30.05 $\mathrm{kg} \mathrm{da}^{-1}$ olarak belirlemiştir. Adalı (2016) Konya koşullarında yaptığı çalışmada ham yağ verimine ait ortalama sonuçların 40.06-114.59 kg da-1 arasında değiştiğini bildirmiştir. Araştırıcıların bulguları çalışmada elde edilen sonuçlardan farklıdır. Bunun sebebinin de kullanılan genotipler, iklim ve toprak şartları olduğu düşünülmektedir.

\section{Sonuç}

Aspir genotiplerine uygulanan farklı azot dozlarının etkilerinin incelendiği bu iki yılık araştırmada incelenen özellikler bakımından en avantajlı sonuçlar $5 \mathrm{~kg} \mathrm{da}^{-1}$ azot dozu uygulamasından ve Linas çeşidinden elde edilmiştir. Yağlı tohumlu bitkilerde yağ oranı çok önemli bir verim öğesidir. Türkiye'deki mevcut 
yağ açığı da göz önüne alındığında özellikle kıraç bölgelerde yüksek yağ oranı bakımından yetiştirilecek önemli bir yağ bitkisi olan aspir bitkisinin tohum ve yağ veriminin geliştirilmesi gereklidir. Ancak bu potansiyelin değerlendirilmesinde uygun yetiştirme tekniklerinin de önemi büyüktür. Bölgelere uygun çeşit ve yetiştirme tekniklerinin belirlenmesi ve belirlenen sonuçların üreticiye ulaşması ve uygulamaya konulması halinde aspir bitkisinin üretimi yaygınlaşacak ve yağ açığımızın kapatılmasında etkisi büyük olabilecektir.

\section{Kaynaklar}

Akbulut, G.B. (2019). Pendimethalin stresine maruz kalan aspir (Carthamus tinctorius L.)'de oluşan bazı biyokimyasal değişiklikler. Harran Tarım ve Gıda Bilimleri Dergisi, 23(1): 90-98.

Anonim (2018). Katı-SıVı Ekstraksiyonu - OMÜ - Kimya Mühendisliği.

kim.muhendislik.omu.edu.tr/files/kim.muhendislik/.. ./Katı- sıvı \%20 Ekstraksiyonu. pdf.

Adalı. M. (2016). Konya Koşullarında Bazı Aspir (Carthamus tinctorious L.) Çeşit ve Hatlarında Verim, Verim Unsurları ve Kalite Özelliklerinin Belirlenmesi. (Yayımlanmamış Yüksek Lisans Tezi) Selçuk Üniversitesi, Fen Bilimleri Enstitüsü, Tarla Bitkileri Anabilim Dalı, Konya.

Arslan, Y. \& Bayraktar, N. (2015). Farklı Azot ve Fosfor Seviyelerinin Kuru Şartlarda Yetiştirilen Aspir (Carthamus tinctorious L.) Bitkisinin Bazı Verim Özellikleri Üzerine Etkisi. Uluslararası Tarım ve Yaban Hayatı Bilimleri Dergisi (UTYHBD), 1(2): 94 - 103.

Arslan, Y. \& Bayraktar, N. (2016). Farklı Azot ve Fosfor Seviyelerinin Kuru Şartlarda Yetiştirilen Aspir (Carthamus tinctorious L.) Bitkisinin Bazı Verim Özellikleri Üzerine Etkisi. Tekirdağ Ziraat Fakültesi Dergisi 13(03):65-73.

Aydın, E. (2012). Bazı Aspir (Carthamus tinctorius L.) Çeşitlerinin Samsun Ekolojik Koşullarında Verim, Verim Unsurları ve Kalite Kriterlerinin Belirlenmesi. (Yayımlanmamış Yüksek Lisans Tezi). Ondokuz Mayıs Üniversitesi Fen Bilimleri Enstitüsü Tarla Bitkileri Anabilim Dalı, Samsun.

Baydar, H. \& Gökmen, O., Y. (2003). Hybrid Seed Production in Safflower (Carthamus tinctorius L.) Following the Induction of Male Sterility by Gibberellic Acid. Plant Breed., 122: 459-461.

Çamaş, N., Çırak, C. \& Esendal, E. (2007). Seed Yield, Oil Content and Fatty Acids Composition of Safflower (Carthamus tinctorius L.) Grown In Northern Turkey Conditions. OMÜ Zir. Fak. Dergisi, 22(1):98-104.

Düzgüneş, O., Kesici, T., Kavuncu, O. \& Gürbüz, F. (1987). Araştırma ve Deneme Metotları (İstatistik Metotları II). Ankara: Ankara Üniversitesi Ziraat Fakültesi Yayınları:1021.

Gencer, O., Sinan, N., S. \& Gülyaşar, S. (1987). Çukurova'da
Sulanmayan Alanlarda Yetiştirilebilecek Aspir (Carthamus tinctorius L.)'de Uygun Sıra Aralığının Saptanması Üzerinde Bir Araştırma. Ç.Ü. Ziraat Fak. Derg. 2(2): 54-68.

Gürsoy, M., Nofouzı, F. \& Başalma, D. (2015). Aspir (Carthamus tinctorius L.) Çeşitlerine Farklı Dozlarda Uygulanan PEG (Polietilenglikol)'in Çimlenme ve Erken Fide Gelişimine Etkisi. 11. Tarla Bitkileri Kongresi, 7-10 Eylül 2015, Çanakkale.

Johnson, R., C.,Bergman, J., W. \& Flynn, C., R. (1999). Oil and Meal Characteristics of Core and Non-core Safflower Accessions from the USDA Collection. Genet. Res. Crop Evol., 46: 611-618.

Katar, D., Arslan, Y. \& Subaşı, I. (2012). Ankara Ekolojik Koşullarında Farklı Azot Dozlarının Aspir (Carthamus tinctorius L.) Bitkisinde Verim ve Verim Unsurları Üzerine Etkisi. Süleyman Demirel Üniversitesi Ziraat Fakültesi Dergisi 7 (2):56-64.

Katar, D., Arslan, Y., Subaşı, İ., Kodaş, R. \& Katar, N. (2015). Bölünerek Uygulanan Azotlu Gübrelerin Aspir (Carthamus tinctorius L.) Bitkisinde Verim ve Verim Unsurları Üzerine Etkisi. Tekirdağ Ziraat Fakültesi Dergisi, 12 (02):11-20.

Kaya, M., Bayramin, S., Kulan, E. \& Özaşık, İ. (2015). Bazı İleri Aspir Hatlarının Eskişehir Koşullarındaki Performansları. U. Ü. Ziraat Fakültesi Dergisi, 29(1): 57-65.

Koç, H., Gümüşçü, G., Üstün, A., Ülker, R., Güneş, A., Kaya, Y. \& Şahin, M. (2009). Konya Şartlarında Aspir Ekim Zamanının Belirlenmesi. Türkiye 8. Tarla Bitkileri Kongresi, 19-22 Ekim 2009, 103-106, Hatay.

Köse, A. \& Bilir, Ö. (2017). Aspir Bitkisinde (Carthamus tinctorius L.) Farklı Sıra Arası Mesafelerin ve Ekim Normunun Taç Yaprak Verimi ve Bazı Bitkisel Özellikler Üzerine Etkisi. Türk Tarım ve Doğa Bilimleri Dergisi 4(1): 40-47.

Özel, A. Gür, A., Demirbilek, T. \& Çopur, O. (2002). Harran Ovası Kuru Koşullarında Farklı Aspir (Chartamus tinctorius L.) Çeşitlerinin Verim ve Bazı Tane Özelliklerinin Belirlenmesi HR.Ü. Ziraat Fakültesi Dergisi, 6(1-2), 29-39.

Özel, A., Demirbilek, T., Çopur, O. \& Gür, A. (2004). Harran Ovası Kuru Koşullarında Farklı Ekim Zamanları ve Sıra Üzeri Mesafelerinin Aspir (Carthamus tinctorius L)'in Taç Yaprak Verimi ve Bazı Bitkisel Özelliklerine Etkis. HR.Ü. Ziraat Fakültesi Dergisi, 8(3-4), 1-9.

Özel, A., Demirbilek, T., Gür A., \& Çopur, O. (2004). Effects of sowing dates and intrarow spacing on yield and some agronomic traits of safflower (Carthamus tinctorius L) under Harran Plain's arid conditions. Turkish Journal of Agriculture and Forestry, 28(6), 413-419.

Öztürk, Ö., Ada, R. \& Akınerdem, F. (2009). Bazı Aspir Çeşitlerinin Sulu ve Kuru Koşullarda Verim ve Verim Unsurlarının Belirlenmesi. Selçuk Tarım ve Gıda Bilimleri Dergisi 23 (50): 16-27.

Sampaio, M., C., Santos, R., F., Bassegio, D., Vasconselos, de E., S.,Silvab, M., de A. \& Secco, DSilva da, T., R.,B. (2016). Fertilizer Improves Seed and Oil Yield of Safflower Under Tropical Conditions . Industrial Crops and Products, 94: 589-595.

Soleymani, A. \& Shahrajabian, M.H. (2011). Effect of planting dates and different levels of nitrogen on 
seed yield and yield components of safflower grown after harvesting of corn in Isfahan, Iran. Research on Crops 12: 739-743.

Yıldırım, B., Tunçtürk, M., Dede, Ö. \& Okut, N., (2005). Aspir (Carthamus tinctorius L.)'de Farklı Azot ve Fosfor Dozlarının Verim ve Kalite Üzerine Etkileri. Yüzüncü Yıl Üniversitesi, Ziraat Fakültesi, Tarım Bilimleri Dergisi (J. Agric. Sci.),15(2): 113-117.

Yılmaz, H., A., Güllüoğlu, L. (1999). Kahramanmaraş Koşullarında Bazı Aspir (Carthamus tinctorius L.) Çeşit ve Hatlarının Verim ile Kimi Tarımsal Karakterlerinin Belirlenmesi. Harran Üniversitesi Ziraat Fakültesi
Dergisi 3 (3-4): 73-86.

Uysal, N., Baydar, H. \& Erbaş, S. (2006). Isparta Populasyonundan Geliştirilen Aspir (Carthamus tinctorius L.) Hatlarının Tarımsal ve Teknolojik Özelliklerinin Belirlenmesi. Süleyman Demirel Üniversitesi Ziraat Fakültesi Dergisi1(1):52-63.

Zareie, S., Golkar, P. \& Mohammadi-Nejad, G. (2011). Effect of Nitrogen and Iron Fertilizers on Seed Yield and Yield Compenents of Safflower Genotypes. African Journal of Agricultural Research, 6(16): 3924-3929. 